\title{
Action Items for Latin-American Chemists and Chemical Societies to Improve Equity and Diversity in Science
}

\author{
Daniel G. Rivera ${ }^{\circledR a}$ \\ ${ }^{a}$ Latin-American Federation of Chemical Associations and Faculty of Chemistry, \\ University of Havana, Zapata y G, Havana 10400, Cuba
}

\begin{abstract}
The chemists from Latin-America need to do more to achieve equality in the scientific world and gain greater recognition by the broader chemical community. For this, we should rethink our strategy to fight for a more inclusive science, not only internationally but also within our region. Raise your hands and take actions to support this movement.
\end{abstract}

Keywords: diversity in science, women in science, gender parity, chemistry conferences

In June 2020, the international community of chemists responded with anger and disappointment to an essay, published online as "Accepted Article" and soon thereafter removed, ${ }^{1}$ expressing opinions that go against the spirit of attaining equality and embracing diversity in academic and research communities. The despair that followed upon publication of this article in a leading chemical journal soon mutated into a movement strongly denouncing the views expressed in that manuscript as obsolete, inaccurate and offensive to women and underrepresented minorities. ${ }^{2,3}$ It was most gratifying to see in commentary posted on social media and science magazines, that the opinions expressed were not representative of the wider chemical community., 4 From a Latin-American perception, many other colleagues and I felt the need to speak out not only as individuals but as representatives of various chemical societies to provide some perspectives on the challenges for Latin-America to improve equity and favor diversity in chemical sciences. By representing the Latin-American Federation of Chemical Associations (FLAQ) as president, 2018-2020 mandate, I would like to use the current momentum to focus both on how to proceed in our region and on our strategy for greater recognition by the broader international scientific community.

First, there is no other way to start this letter than by expressing-on behalf of FLAQ-the most emphatic condemnation of any point of view, belief or action that either supports racism and discrimination in all its forms or is opposed to a more inclusive and diverse scientific scenario in our region and the world. FLAQ, since its

*e-mail: dgr@fq.uh.cu foundation in 1959, has gathered and represented the most important chemical societies, associations and colleges of Latin-America, ${ }^{6}$ and continues (re)incorporating either newly formed or previously affiliated associations. As stipulated by its principles and statutes, FLAQ is an inclusive and egalitarian organization of scientific associations that share the aim of promoting and supporting the chemical sciences for the benefit and well being of our respective countries. FLAQ provides a snapshot of Latin-America, which is one of the most ethnically diverse regions in the world. As such, it is a mixture of races, colors, customs, and beliefs that collectively define not only our social values but also our way of planning, conducting and communicating science. Whereas this letter is directed to all people involved in science, in many parts I use the term "we" to refer to Latin-American scientists, working or not in this region, as I believe we can do better to represent our region in the international community. In addition, some of the actions here proposed indeed depend not only on our will to implement them but on having the funds to do so. However, it is also true that the will of scientific leaders can influence decision-makers to do differently with the same budget. I would like this piece to be seen as a call to rethink our future actions at the time we advocate for a more inclusive agenda.

Do we have minority and discrimination problems in Latin-American science too?

Perhaps the first question would be: do we have minorities in the sense generally referred to in Europe, Canada and the United States of America (USA)? Strictly speaking, the whole of Latin-America proudly is made up of what, for example, in the USA are considered 
"minority groups", with reference to Black, Asian, Latin, or indigenous populations. Therefore, although the perspective from which we have to look at our "minority issue" may be different from that of scientists from Europe and the USA, the representation problem is essentially the same. We would be naive if we do not recognize that in many Latin-American universities, certain populations and social classes are extremely underrepresented in both undergraduate and post-graduation programs, ${ }^{7}$ not only in sciences but also in engineering and many other academic areas. Of course, the reasons for this are largely socioeconomic, and they vary substantially from one country to another, because each country has very different minority issues as well as economic and political systems. In any case, one would be inclined to accept that our region also shares the same problems of other parts of the world regarding the significant underrepresentation of certain population classes in physical and life science graduate programs and university faculty positions. How each country faces and addresses this problem is not the subject of this letter, but as scientists and educators, we should embrace the movement calling for "actions not just words". ${ }^{3}$ In Latin-American universities, "minorities" are not only Black, indigenous or Asian populations (whose percentages vary a lot in each country), but also students from disadvantaged social classes who may have taken more time to complete their studies because they received poorer basic formation or had to work for a living, thus dedicating less time to study. Any of them could be a bright scientist in the future if proper opportunities are given. By no means should we discriminate or stop scientific or professional progression based on how people look or what their social background is. Science, more than anything, is made more powerful when it is nourished by all kinds of diverse thoughts and life experiences.

In the above-mentioned essay, ${ }^{1}$ it was indicated that the diversity of the workforce has a negative influence on organic synthesis. This aspect was rightfully criticized because it was lacking in supporting reference or data; indeed, it is also refuted by numerous researchers statingand demonstrating with data $^{8}$-that research groups can become more productive when they are more diverse and international. Today one can see that among the most successful research groups are those integrating students from different parts of the world. There is also a generalized movement in universities and chemical societies to support diversity in research groups ${ }^{5}$ and faculty positions. ${ }^{3}$ For Latin-American students that choose and can study abroad, $\mathrm{PhD}$ programs and internships in Europe, Canada, and USA are the preferred destination. As they integrate not only with the nationals but also with students and postdocs from Asia, Africa, etc., they can learn the scientific and personal benefits of being part of a multicultural research group. The positive experience that these scholars bring back to their home countries can be crucial not only for their future as educators or entrepreneurs but also to reshape the composition and behavior of the groups where they reintegrate after returning.

What can we do to favor diversity of the workforce in Latin-American research groups?

In addition to favoring, at all institutional levels, the inclusion of all types of underrepresented groups in science careers and post-graduate programs, we scientists should diversify research groups by actively integrating members of different social classes, countries and continents. Chemical societies, universities, companies, and we, as individuals, can do a lot to promote actions in this regard. Here are some examples:

(i) Give the same opportunities to all students and graduates. The recognition that talent is everywhere and not only in those who received better chances early in life (e.g., basic education) results in being more open to giving opportunities to students arising from minority populations or disadvantaged social classes. Like anyone else, such students can have a special talent for science and become highly productive and talented researchers. This applies to careers in academia and the chemical/pharmaceutical industries, which are widely represented in our chemical societies. As they hire most of the graduates of our universities, they should consider the power of diversifying the scientific workforce. Examples of highly diverse and successful-in terms of creativity, productivity and revenues-technological enterprises are very common, especially in North America.

(ii) Implement bidirectional exchange programs within Latin-America and between Latin-America and other continents. Unfortunately, most Latin-American exchange programs are intended to send students abroad, while just a few allow bidirectional exchange. It is not enough to send our best students to be trained in Europe, Canada and the USA, thus making the destination groups more diverse. We should also favor the diversity of our own research programs by bringing international students to work in our groups. As a positive example, I have been part of a very international group in a federal university in Brazil, which, in addition to nationals, included $\mathrm{PhD}$ students and postdocs from Colombia, Cuba, Pakistan, India, Portugal, and Germany. This diversification of the workforce leads, for example, to seminars and daily lab work conducted 
in English, while each student incorporates their own experience to enrich scientific productivity.

(iii) Increase the internationalization of doctoral programs in science. The tendency of some LatinAmerican universities to give priority to national students is detrimental to the pursuit of a more diverse scientific workforce. On the other hand, I have seen positive examples in universities of Mexico, Chile and Brazil, which have internationalized considerably their doctoral programs in chemistry, although they are still mostly populated by Latin-American students. Some of our best Latin-American universities certainly have the capacity and quality to welcome graduate students from Europe, the USA, China or India, just to mention areas of large populations with significant contributions to science. This action should not be seen as funding spent on educating individuals from other countries but as an investment in the internationalization of our research groups. Latin-American students can learn a lot from the competitiveness found in research of scholars from other regions.

(iv) Attract visiting professors. Looking at more senior staff, we have to do more than merely invite professors from abroad to give a seminar once per month. We need to host postdocs and visiting professors to be fully integrated temporarily in our groups and bring their expertise and perspective to our universities. Some of these foreign academics, upon returning to their home countries, will eventually become editors of chemical journals and occupy decision making positions at universities, thus helping to boost the position of Latin-America in the international scientific scenario and provide opportunities for Latin American scientists in the global setting. While hiring, even temporarily, foreign professors might be financially difficult for many Latin-American countries, it is viable for various Latin-American universities and science funding agencies from our region.

(v) Open our minds to mentoring international students. Even if they come from countries whose customs or religion we do not understand well, be open-minded to receive and train students with a different culture and language from yours. Very often, those students integrate successfully and contribute to diversifying the skills and research topics of your group. Even neighboring countries sometimes have very different teaching systems, and those students might have learned specific aspects of chemistry differently from what you teach to your own. The diversity of minds, languages and working systems can never be negative for creativity and innovation.
How do we face the gender issue in Latin-American science?

In this relevant subject for our societies, Latin-America faces the same challenges as other international scientific communities. It has been recognized that in our region the gender gap in education is not as pronounced as in other parts of the world. ${ }^{9}$ However, gender disparity in natural sciences is still present in most Latin-American countries, with a few documented exceptions. ${ }^{10}$ In general, the percentage of women's representation in Latin-American undergraduate and doctoral programs in sciences is not low but it decreases significantly when moving upward to more senior positions. ${ }^{11,12}$ Interesting studies shed light on the pre-existing biases, possible causes and actual dimension of this phenomenon in different Latin-American areas. ${ }^{11-14}$

From FLAQ's perspective, one aspect that we can celebrate is how well-represented women are in both the scientific programs and committees of the Latin-American Congresses of Chemistry (CLAQs). In the last $33^{\text {rd }}$ CLAQ of $2018,{ }^{15}$ held in Havana, Cuba, $67 \%$ of the more than 1200 participants were women, and 11 out of the 14 members of the Scientific Committee and section coordinators were women, including the President. In the next CLAQ to be held in Colombia in October 2021, ${ }^{16}$ the President of the Scientific Committee is also a woman. All this is proof of the outstanding quality of female researchers in Latin-American chemical societies. However, in the CLAQs and other conferences hosted in Latin-America, the majority of invited speakers still are men; therefore, a greater commitment to gender equity could be shown by the organizing committees. In general, much work remains to be done in our region before we can rest assured equality and inclusion has been reached. Here are some actions that we could implement.

(i) As chemical societies: advocate at all stages for equal opportunities for men and women in ALL aspects of science, including access to under- and postgraduate programs, promotion to faculty positions in universities, talks in scientific conferences, and press coverage of results. This is an important step forward towards providing equity in the competitive realm of scientific research.

(ii) Do not forget the industry. Whereas the academic sector has recognized problems with gender inequality and taken actions to improve it, the perception of various colleagues who gave me suggestions for this article is that the Latin-American chemical and biopharmaceutical industry is lagging in facing this problem. Therefore, it is important to use the influence of our scientific societies to promote the 
debate on gender equity in this industrial sector. Many industrial leaders and decision-makers are members of our chemical societies and they could be positively influenced to take actions in this regard.

(iii) As an individual, advocating for equal opportunities is not enough. ${ }^{3}$ In any academic or industrial position we occupy, we must actively ensure fairness in the opportunities given to women as compared to men. This commitment begins from the moment we choose how many women and men integrate our research groups and continues when we organize a symposium and seek for a proper gender balance in the speaker slots. ${ }^{17}$ Taking care of a proper balance in scientific conferences or any other scientific scenario is not-and can never be seen as-a favor we do for underrepresented groups, ${ }^{18} \mathrm{instead}$ it follows from the fact that diversity and inclusiveness generate better conferences, insightful discussions, and ultimately better science.

How underrepresented is Latin-America in Chemistry conferences and top journals?

In my perspective, the answer to this question is clear: very much. An example of this is the rather low number of Latin-American articles in the leading journals of the American Chemical Society, the Royal Society of Chemistry, Elsevier, Wiley-VCH, and Springer Nature, and in the editorial boards of those journals. ${ }^{3,19}$ I do not intend to compare in numbers the scientific contribution of LatinAmerica with that of China, India and Japan, among others, because the reality is that our region has systematically abandoned the long-term investment in scientific and technological development. Various factors such as limited access to grants, low budgets for laboratory facilities and salaries of scientists, and high cost and inadequate supply of reagents and modern instrumentation, indeed, contribute to the low scientific productivity of the region..$^{20}$ However, the number of scientists, research institutions and publications has certainly increased over the last two decades and I do believe we are undervalued as a scientific community.

The underrepresentation of Latin-America chemists in the mainstream journals and conferences might have several causes, including the actual quality of our science, the lack of proper opportunities and also our insufficient activism and leadership in the international scenario. Too often I hear complaints from Latin-American colleagues about the editorial reject-without-review that has been implemented by some top journals to deal with the large volume of submissions. While this can be fundamentally unfair to all researchers, I truly believe that underrepresented regions like Latin-America are more affected by this trend. The global community of scientists needs to devise a more equitable, inclusive system that does not put at a disadvantage underrepresented regions and those seeking to establish themselves as leaders in the global scientific enterprise. However, we, Latin-Americans, have to do more ourselves to be better recognized in the international community. For example, during interaction with journal editors for the preparation of this letter, it was raised the point regarding the low number of articles submitted by Latin-American authors to some journals that are world leaders in their specific fields. This and other facts suggest that our position should not be self-indulgent and blaming the publishing system of the leading journals or the selection of speaking slots in international conferences but to be more competitive in publicizing our science and gain our space in the international scenario. Here are some actions that we could implement for such a purpose.

(i) As an individual: be more proactive in the scientific interaction with the leaders of your specialty, especially editors, members of editorial boards and conference chairs. Help them understand the potential of LatinAmerican science and encourage them to give opportunities to researchers of this region. If possible, invite them to visit your university to evaluate firsthand the relevance of your results and those of your colleagues.

(ii) Advocate in international congresses and personal interactions with decision-makers for fairer publishing opportunities such as the option of double-blind reviewing. This works not only for the benefit of underrepresented communities but also for younger or less known scientists from all countries.

(iii) Trust more in your science. Do not hesitate to ask the editor to reconsider the decision to not send your manuscript to peer-review. At this stage, the persuasive content of the cover letter is crucial to convince him/ her of the novelty and impact of your results. Similarly, do not be afraid of requesting an additional reviewer in the case of contradictory or partially biased reports. Speak out if you see any discriminatory or chauvinist comment in the referee report-you can ask the editor not to accept such a report and seek another reviewer. (iv) Nominate prominent colleagues from LatinAmerica-either if they currently work in our region or not-to international awards and editorial positions of top Chemistry journals. It is crucial to have people who know the Latin-American reality and potential in the editorial boards.

(v) As chemical societies: negotiate with international editors to dedicate special issues to publish scientific research conducted in Latin-America. This is especially 
easy these days with the practice of Virtual Issues. Here, it is worth mentioning that members of the Brazilian chemical community are very active in both attracting editors to chemistry conferences and negotiating with them the dedication of special issues to publish results presented in those conferences. This is an example to follow by the organizing committees of the CLAQs and other chemistry conferences to be held in Latin-America. (vi) Use the CLAQs and other national chemistry conferences in the region as platforms for launching the internationalization of the Latin-American chemical sciences. It is not enough to increase the Latin-American participation in conferences abroad but we should bring scientific leaders to conferences in our region. Invite them to look at the posters of our students and listen to the talks of our best scientists.

(vii) Latin-American chemical societies should implement a long-term strategy to improve the quality and visibility of our journals. Among many other things, we have to seek that both the editorial boards and the authors are more international and diverse. It is also important to convince the top Latin-American researchers to send some of our best results to these journals to increase citations and visibility.

Overall, important aspects that can contribute to increasing the representation of Latin-America in the Chemistry conferences and top journals and thus improve the international recognition are: (i) to continue improving the scientific level of Latin-American academics and universities (this is indeed the most important one), (ii) to be more effective in the interaction with scientific leaders and in the way of communicating our results, and (iii) to increase the representation of Latin-American scientists in the editorial boards and convince editors and publishers of the potential of the scientific research done in our region.

In conclusion, Latin-American science, and especially Chemistry, is not exempt from the problems associated with inequality and the low diversity of other research communities. This letter outlined some ideas of what we can do both as individuals and as members of the chemical societies to improve the inclusion of underrepresented groups in scientific activities and increase the representation of the Latin-American chemistry in the broader international community. We must not only actively repudiate and act against any discriminatory word or action but also help to build consensus in our classrooms, research labs, and faculty departments about the benefits of a more diverse and open-to-the-world research and education environment. As we fight for a more inclusive science within our countries and continent, we must also seek a better balance between meritocracy and gender and minority representation. There is a long way to go to improve the recognition of our region in the scientific world, starting with the internationalization of our research groups and journals. This will also require us to not only speak out when we see ourselves, as LatinAmericans, underrepresented in any possible scenario (e.g., international conferences) but also take actions by nominating and endorsing our peers to editorial positions and research awards. We are not a minority in the world, but in science, we are considered as such, and much can be done to change that perception. Finally, we must treat others in our region as we want to be treated in the world, with equal opportunities to allow everyone to show his/her scientific potential regardless of nationality, gender, race, beliefs, and sexuality.

The statements against racism and the discrimination of women and minorities in science, as well as the call for a more diverse and inclusive science, are expressed on behalf of FLAQ and all its member societies. However, other views and perspectives outlined in this letter are those of the author and not necessarily of other members of FLAQ.

\section{Supplementary Information}

The content of this Letter appears as Editorial jointly published in the American Chemical Society journals Organic Letters (10.1021/acs.orglett.0c02585), The Journal of Organic Chemistry (10.1021/acs.joc.0c01893), Organometallics (10.1021/acs.organomet.0c00529) and Inorganic Chemistry (10.1021/acs.inorgchem.0c02344).

\section{Acknowledgments}

I am very grateful to the members of the Board of Directors of the Latin-American Federation of Chemical Associations (FLAQ) and to the many colleagues and journal editors who gave suggestions about this topic.

\section{References}

1. https://onlinelibrary.wiley.com/page/journal/15213773/ homepage/news\#vchnews49471, accessed in July 2020.

2. https://www.gdch.de/service-information/nachricht/article/ stellungnahme-zum-beitrag-von-tomas-hudlicky-in-derangewandten-chemie.html, accessed in July 2020.

3. Sandford, M. S.; J. Am. Chem. Soc. $2020,142,11317$.

4. https://cen.acs.org/research-integrity/ethics/Essay-criticizingefforts-increase-diversity-in-organic-synthesis-deleted-afterbacklash-from-chemists/98/web/2020/06, accessed in July 2020 . 
5. https://www.rsc.org/news-events/articles/2020/jun/id-jointsocieties-statement, accessed in June 2020.

6. http://flaq1959.org, accessed in July 2020.

7. https://diverseeducation.com/article/78145/, accessed in July 2020.

8. Hofstra, B.; Kulkarni, V. V.; Munoz-Najar Galvez, S.; He, B.; Jurafsky, D.; McFarland, D. A.; Proc. Natl. Acad. Sci. USA 2020, 117, 9284.

9. https://www.universityworldnews.com/post.php?story= 20180711134740581, accessed in July 2020.

10. https://twas.org/article/women-science-cuba, accessed in July 2020.

11. López-Aguirre, C.; Tapuya: Lat. Am. Sci. Technol. Soc. 2019, 2,356

12. Valentova, J. V.; Otta, E.; Silva, M. L.; McElligott, A. G.; PeerJ 2017, 5, e4000.

13. Franco-Orozco, C. M.; Franco-Orozco, B.; Front. Astron. Space Sci. 2018, 5, 24.

14. Alvarez, L.; Pérez, A.; Cobas, M. In Women in Physics, The IUPAC International Conference, AIP Conference Proceedings 628; American Institute of Physics: New York, 2002, p. 151-152.

15. http://www.chemistrycuba.com/, accessed in July 2020.

16. http://claq2020.com/, accessed in July 2020.

17. Ford, H. L.; Brick, C.; Azmitia, M.; Blaufuss, K.; Dekens, P.; Nature 2019, 576, 32.
18. https://cen.acs.org/careers/diversity/Fewer-underrepresentedminority-scientists-are-invited-to-give-talks/97/web/2019/12, accessed in July 2020.

19. Burrows, C. J.; Huang, J.; Wang, S.; Kim, H. J.; Meyer, G. J.; Schanze, K.; Lee, T. R.; Lutkenhaus, J. L.; Kaplan, D.; Jones, C.; Bertozzi, C.; Kiessling, L.; Mulcahy, M. B.; Lindsley, C. W.; Finn, M. G.; Blum, J. D.; Kamat, P.; Choi, W.; Snyder, S.; Aldrich, C. C.; Rowan, S.; Liu, B.; Liotta, D.; Weiss, P. S.; Zhang, D.; Ganesh, K. N.; Atwater, H. A.; Gooding, J. J.; Allen, D. T.; Voigt, C. A.; Sweedler, J.; Schepartz, A.; Rotello, V.; Lecommandoux, S.; Sturla, S. J.; Hammes-Schiffer, S.; Buriak, J.; Steed, J. W.; Wu, H.; Zimmerman, J.; Brooks, B.; Savage, P.; Tolman, W.; Hofmann, T. F.; Brennecke, J. F.; Holme, T. A.; Merz Jr., K. M.; Scuseria, G.; Jorgensen, W.; Georg, G. I.; Wang, S.; Proteau, P.; Yates III, J. R.; Stang, P.; Walker, G. C.; Hillmyer, M.; Taylor, L. S.; Odom, T. W.; Carreira, E.; Rossen, K.; Chirik, P.; Miller, S. J.; Shea, J.-E.; McCoy, A.; Zanni, M.; Hartland, G.; Scholes, G.; Loo, J. A.; Milne, J.; Tegen, S. B.; Kulp, D. T.; Laskin, J.; Org. Lett. 2020, 22, 4919.

20. Ciocca, D. R.; Delgado, G.; Cell Stress Chaperones 2017, 22, 847.

Submitted: June 26, 2020

Published online: August 17, 2020 